\title{
The needs of parents of children with visual impairment studying in mainstream schools in Hong Kong
}

\author{
Florence MY Lee *, Janice FK Tsang, Mandy MY Chui
}

\section{A B S T R A C T}

Objectives: This study attempted to use a validated and standardised psychometric tool to identify the specific needs of parents of children with visual impairment studying in mainstream schools in Hong Kong. The second aim was to compare their needs with those of parents of mainstream school children without special education needs and parents having children with learning and behavioural problems.

Design: Cross-sectional survey.

Setting: Mainstream schools in Hong Kong.

Participants: Parents of 30 children with visual impairment who were studying in mainstream schools and attended assessment by optometrists at Child Assessment Service between May 2009 and June 2010 were recruited in the study (visual impairment group). Parents of 45 children with learning and behavioural problems recruited from two parent support groups (learning and behavioural problems group), and parents of 233 children without special education needs studying in mainstream schools recruited in a previous validation study on Service Needs Questionnaire (normal group) were used for comparison. Participants were invited to complete a self-administered Service Needs Questionnaire and a questionnaire on demographics of the children and their responding parents. The visual impairment group was asked additional questions about the ability of the child in coping and functioning in academic and recreational activities.

Results: Needs expressed by parents of the visual impairment group were significantly higher than those of parents of the normal group, and similar to those in the learning and behavioural problems group. Parents of children with visual impairment expressed more needs for future education and school support than resources for dealing with personal and family stress.

Conclusion: Service needs of children with visual impairment and their families are high, particularly for future education and school support. More study on the various modes of accommodation for children with visual impairment and more collaborative work among different partners working in the field of rehabilitation will foster better service for these children and their families.

\section{Hong Kong Med J 2014;20:413-20}

DOI: $10.12809 / \mathrm{hkmj} 134202$

FMY Lee *, FHKCPaed, FHKAM (Paediatrics)

JFK Tsang, MSocSc

MMY Chui, MSc

Child Assessment Service, Department of Health, 2/F, 147L Argyle Street, Kowloon City, Hong Kong

* Corresponding author: florence_lee@dh.gov.hk

New knowledge added by this study

- Needs expressed by parents having children with visual impairment (VI) are significantly higher than those of parents of mainstream school children without special education needs, and similar to those of parents of children with learning and behavioural problems.

Implications for clinical practice or policy

- Clinicians have to be sensitive to the service needs presented by children with VI and their families. More collaborative work among different partners working in the field of rehabilitation will foster better service for children with VI and their families.

\section{Introduction}

Parents of children with developmental difficulties face many challenges with child handling and coping with school. In helping these children, the needs of their caretakers should not be ignored. Besides, better understanding of the needs of their parents could shed light on the desired direction of general service planning, and enable optimal use of our resources. The formulation of service needs in collaboration with parents instead of only by the health care professionals helps to facilitate efficient family support implementation. This can also serve as pre-intervention measurement for reliable outcome evaluation. ${ }^{1}$ Child Assessment 


\section{就讀香港主流學校的視障兒童的家長的需要}

李敏尤、曾鳳琼、崔敏儀

目的：本研究嘗試使用一個經驗證和標準化的心理測量工具，找出在 香港主流學校就讀的視障兒童的家長的特定需要, 並比較在主流學校 中央須接受特殊教育以及有學習和行為問題的兩組學童, 其家長的需 求。

設計：橫斷面調查。

安排：香港的主流學校。

參與者：就讀主流學校並於2009年5月至2010年6月期間於衞生署兒 童體能智力測驗服務接受視光師評估的 30 名視障兒童 (視障組) 的 家長均參與本研究。另有兩組作比較研究, 分別來自兩個家長支援小 組內的 45 名有學習和行為問題的兒童的家長（學習和行為問題組）, 以及沒有特殊教育需要並在主流學校就讀的233名兒童的家長（正常 組）；他們均參與之前一項有關「服務需要問卷」的驗證研究。本研 究的參與者須自行填寫一份「服務需要問卷」, 以及另一份有關孩子 和家長的背景資料。視障組須額外填寫有關孩子適應學習和康樂活動 中遇到的問題。

結果 : 視障組的家長表達的需求明顯高於正常對照組, 並與學習和行 為問題組相若。視障兒童的家長表示對於未來的教育和學校支援的需 求比處理個人和家庭壓力為大。

結論：視障兒童及其家庭的服務需求很大，尤於未來的教育和學校支 援為甚。須進行更多有關視障兒童的適應模式和在康復領域中不同的 合作夥伴的協同工作, 以便對這些孩子和其家庭提供更好的服務。

Service (CAS) of the Department of Health comprises multidisciplinary professionals and provides comprehensive developmental assessment and rehabilitation prescriptions to children with developmental and behavioural problems in Hong Kong. Recently, CAS developed a Service Needs Questionnaire (SNQ) to examine the needs of parents of children with learning and behavioural problems including dyslexia and attention-deficit hyperactivity disorder (ADHD). The scale has undergone formal procedures of scale validation and standardisation, and can be used as a reliable tool for mapping the needs of parents with children with different developmental disabilities. ${ }^{2}$

Although many studies have investigated service needs of disabled children, ${ }^{3-5}$ few have attempted to investigate service needs of children with visual impairment (VI) and their families. The parents' perceived needs based on ethnicity, and the degree of vision loss in toddlers from Latino and Anglo backgrounds were reported based on qualitative description. The future of their children was the universal concern among parents. Other concerns were household finances, adequacy of services, and the impact on siblings. The perceived insensitivity and lack of information from professionals were sources of difficulty and frustration. ${ }^{6}$ On studying the perspective of parents of children with VI, it was noted that many experienced difficulties, frustration, and concerns about the child's future; there was also lack of helpful information, social isolation, and inadequate support from school and community. ${ }^{7}$ Parents of children newly diagnosed with VI and/or ophthalmic disorders in a tertiary level centre had a tendency to identify information as their greatest need, almost irrespective of the amount or type actually provided. ${ }^{8}$

In the local setting, there are limited needs analysis studies on disabled children, and none targeted towards children with VI in mainstream schools. In Guangzhou, however, focus group interviews were conducted in a qualitative study to elicit the experiences of 23 Chinese parents in caring for their children with developmental disability who were residents of the Mental Retardation Unit in a Maternal and Children Hospital. Five categories of needs were identified: parental, informational, attitude towards the child, coping, and support. ${ }^{9}$

In Hong Kong, the Education Bureau encourages students with diverse learning needs to receive appropriate education alongside their peers so as to help them develop their potential. While special schools cater for children with significant developmental disabilities, children with milder developmental disabilities are integrated into mainstream schools. In mainstream schools, students have diverse special education needs (SEN). Most have learning and behavioural problems, and few have physical and/or sensory problems. This study is the first local attempt to use a validated and standardised psychometric tool to identify the specific needs of parents of children with VI studying in mainstream schools. The study also attempted to examine if their needs are different from those of parents of children without SEN studying in mainstream schools and parents of children with learning and behavioural problems. Better understanding of the parental needs will help in planning for future service and support for these children and their families.

\section{Methods}

\section{Participants and recruitment procedures}

\section{Parents of children with visual impairment}

Child Assessment Service of the Department of Health provides comprehensive assessment, rehabilitation prescriptions, and management services to children and families in Hong Kong. In 2012, the number of referrals served by CAS was 8773 with children aged below 10 years accounting for $98.4 \%$ of the referrals (written communication, CAS, 2013). The number of children aged below 10 years was estimated to be 252100 in Hong Kong in 2012. ${ }^{10}$ Between 2006 and 2010, the number of newly 
diagnosed visually impaired children in CAS ranged from 28 to 37 every year. ${ }^{11}$

Parents of 30 children with VI who were studying in mainstream schools and who underwent assessment by optometrists at CAS between May 2009 and June 2010 were recruited to participate in the study (VI group). The parents were asked to reply once for each child. The purpose of the study was clearly explained, and a consent form was signed by each respondent. All 30 consented to participate, but four failed to complete the questionnaire. The analysis reported in this study was therefore based on data from 26 participants who completed the $\mathrm{SNQ}$. The degree of VI ranged from mild low vision to severe low vision, according to the definition for the provision of various rehabilitation services by the Hong Kong Government. ${ }^{12}$ The visual acuity for mild low vision was defined as from $6 / 18$ to better than $6 / 60$, moderate low vision was from $6 / 60$ to better than $6 / 120$, and severe low vision was $6 / 120$ or worse in the better eye.

\section{Parents of children with behavioural and learning problems}

Parents of children with learning and behavioural problems were recruited from two local parent support groups (LB group). Parent support group is a self-help organisation which serves the common interests of parents having children with same or similar disability or disease. Behavioural and learning problems are the major SEN concern in mainstream schools. In Hong Kong, there are a number of parent support groups for parents having children with learning and behavioural problems. Two parent support groups, the Hong Kong Association for AD/ $\mathrm{HD}$ and the Hong Kong Association for Specific Learning Disabilities, were invited to participate in this study as apparently they have the biggest membership and the longest history in serving children with such developmental problems and disability. All parents attending their annual meetings were invited to participate on a voluntary basis, and 45 participated. A letter stating the purpose of the study was given and a consent form was signed by each respondent. The analysis reported in this study was based on the 43 participants who completed the SNQs. Despite the constraint of such convenience sampling, efforts have been paid to enhance the representativeness of the selected participants.

\section{Parents of mainstream school children without special education needs}

Anonymous raw data of parents of children attending mainstream primary schools $(\mathrm{n}=233)$ collected in Leung et al's study for the development of SNQ was accessed and analysed. ${ }^{2}$ Three primary schools, one each from the territory's administrative regions, were requested to randomly select 135 students to participate using a random number generator. The schools distributed the questionnaires to parents; 246 parents returned the questionnaires in sealed envelopes (response rate $60.7 \%$ ) and 233 provided complete data. Among the 233 participants from the primary school group, 33 with reported behavioural/ learning difficulties were excluded, and 200 were included in the comparison (normal group). Since SNQ was jointly developed by CAS and Leung et al, ${ }^{2}$ the research data were archived and shared between the two parties. Upon an agreement between CAS and Leung et $\mathrm{al}^{2}{ }^{2}$ the research data were retrieved and analysed by authors. Legitimacy of such arrangement was documented in the research protocol written for SNQ project. The data retrieved and being analysed for this study included SNQ scores and demographics of participants.

\section{Measures}

Participants of the VI group and LB group were asked to complete the SNQ and a questionnaire on the demographics of the children and their responding parents. The VI group was asked 12 additional questions about the children's ability to cope and function in academic and recreational activities.

\section{Service Needs Questionnaire}

Service Needs Questionnaire had 27 items. It was subdivided into two parts, and was selfadministered by the informants. The first part consisted of eight items on personal and family stress. Participants rated each item on a 5-point scale from 1 (disagree very much) to 5 (agree very much). The second part consisted of 19 items on need for various services. Participants rated each item on a 5-point scale from 1 (do not endorse at all) to 5 (endorse a lot). This scale has been validated for use in Chinese parents. ${ }^{2}$ The areas of need which can be identified by SNQ included the need for school support, need for information, and need for support on family functioning.

This questionnaire was developed among Chinese families and it showed satisfactory psychometric properties. ${ }^{2}$ For validity, the SNQ total score (5 categories) correlated positively (correlation $=0.55$ ) with Parenting Stress Scale, and it could differentiate between parents of children diagnosed with learning/behavioural problems and those attending normal primary schools $(\mathrm{t}(336)=12.07 ; \quad \mathrm{P}<0.001 ; \quad \mathrm{d}=1.42)$. For internal consistency and reliability, the reported Cronbach's alpha was 0.96 and intra-class correlation was 0.76 , respectively. In Leung et al's study, ${ }^{2}$ Rasch analysis was conducted to demonstrate the primary psychometric properties of SNQ. It was shown that SNQ measured a single construct need (ie unidimensionality); was able to distinguish strata of needs in children with developmental disabilities; 
had sufficient items to capture needs of children with developmental disabilities; and there was a meaningful item hierarchy. Construct validity and reliability of SNQ were also shown by additional analyses. As SNQ serves to describe needs of children with developmental disabilities, the reported psychometric properties were sufficient to serve this aim.

\section{Ability of a child to cope and function in academic and recreational activities}

There were 12 additional questions designed to obtain some descriptive information from VI group on children's functional needs, school coping, and difficulties encountered in academic and recreational activities. Participants were asked to report positive or negative answers regarding each question and requested to give examples if the answers were positive. Some examples of these questions were "Which is the most difficult subject for you? Please state problems encountered, if any"; "Are there any problems encountered in recess or lunch time? If yes, please state the problem and the reason".

\section{Demographic information}

Participants were requested to supply demographic information about themselves and their children.

The study was approved by the Ethics Committee of the Department of Health, Hong Kong SAR Government.

\section{Data analysis}

Descriptive statistics, frequency distribution, and means were used to examine the profiles of participants. Since Leung et al's study ${ }^{2}$ showed difference among parents of children with learning and behavioural problems and those of normal children, our hypothesis was that there was a difference between the needs of parents of VI group and those of normal group. The data were examined before hypothesis testing so that appropriate statistical tests could be applied. Independent $t$ test and one-way analysis of variance (ANOVA) were used to analyse the differences in means between two or more than two groups if the corresponding test assumptions were fulfilled. Otherwise, KruskalWallis test was used to analyse the differences in mean rank for comparison of more than two groups. The statistical analyses were performed using the Statistical Package for the Social Sciences (Windows version 19.0; SPSS Inc, Chicago [IL], US). ${ }^{13}$ Statistical significance was set at $\mathrm{P}<0.05$ (two-tailed).

TABLE I. Demographics of participants in different study groups

\begin{tabular}{|c|c|c|c|}
\hline & VI group $(n=30)$ & $\begin{array}{c}\text { Normal group } \\
(n=233)\end{array}$ & LB group $(n=45)$ \\
\hline \multicolumn{4}{|l|}{ Frequency } \\
\hline Child (male) & $20(66.7 \%)$ & $119(51.1 \%)$ & $32(71.1 \%)$ \\
\hline Father's education (upper secondary or above) & $16(53.3 \%)$ & $123(52.8 \%)$ & $28(62.2 \%)$ \\
\hline Mother's education (upper secondary or above) & $18(60.0 \%)$ & $127(54.5 \%)$ & $34(75.6 \%)$ \\
\hline Father is employed & $19(63.3 \%)$ & $183(78.5 \%)$ & $29(64.4 \%)$ \\
\hline Mother is employed & $11(36.7 \%)$ & $104(44.6 \%)$ & $20(44.4 \%)$ \\
\hline Nuclear family & $21(70.0 \%)$ & $163(70.0 \%)$ & $32(71.1 \%)$ \\
\hline Married & $26(86.7 \%)$ & $212(91.0 \%)$ & $34(75.6 \%)$ \\
\hline Publicly funded school & $28(93.3 \%)$ & $227(97.4 \%)$ & $41(91.1 \%)$ \\
\hline \multicolumn{4}{|l|}{ Mean } \\
\hline Child age* (years) $^{*}$ & 9.34 & 8.52 & 10.55 \\
\hline Child's length of residence in Hong Kong ${ }^{\star}$ (years) & 9.26 & 7.68 & 10.43 \\
\hline Mother's age ${ }^{*}$ (years) & 41.32 & 38.88 & 43.41 \\
\hline Father's age* (years) & 47.00 & 44.24 & 46.93 \\
\hline Mother's length of residence in Hong Kong (years) & 28.40 & 24.40 & 36.62 \\
\hline Father's length of residence in Hong Kong ${ }^{\star}$ (years) & 41.24 & 37.27 & 43.24 \\
\hline No. of children in family* & 1.88 & 1.87 & 1.76 \\
\hline
\end{tabular}

Abbreviations: $L B=$ learning and behavioural problems; $V I=$ visual impairment

* Cases with missing data in any one of the seven interval variables (child's age, child's length of residence in Hong Kong, mother's age, father's age, mother's length of residence in Hong Kong, father's length of residence in Hong Kong, No. of children in family) were excluded from calculation. Hence, the denominators for VI group, normal group, and LB group were 25, 195, and 29, respectively 


\section{Results}

\section{Characteristics of participants}

The demographic characteristics of parents in the three groups were comparable. Compared with the normal group, a higher proportion of boys were noted in VI and LB groups and the mean age of children in LB and VI groups was slightly higher. The parents of LB group and VI group resided in Hong Kong for longer than those of the normal group. Fewer fathers of LB and VI groups were employed compared with those of normal group (Table 1).

\section{Intragroup comparison of Service Needs Questionnaire in visual impairment group}

Within the VI group, 26 participants with completed SNQ data were included in the analysis. The most common medical cause for VI was ocular or oculocutaneous albinism $(n=10)$. Other causes included cataract $(n=3)$, retinopathy of prematurity $(n=2)$, aniridia $(n=2)$, retinal dystrophy $(n=2)$, septooptic dysplasia $(n=1)$, high refractive error $(n=1)$, and intraventricular haemorrhage $(n=1)$; investigation results were still pending for four cases.

Their cognitive abilities were mostly within the low average to high average range. One had mild mental retardation, two had limited intelligence, and one had superior intelligence. Regarding comorbid developmental disabilities, 11 (42\%) children in the VI group had one or more than one type of developmental disability apart from VI. One had mild-grade mental retardation, four had dyslexia/ risk for dyslexia, two had ADHD, one had autistic spectrum disorder, two had mild hearing loss, and one had mild anxiety problem. There was no significant difference in SNQ total score between those with or without co-morbid conditions $(\mathrm{t}(24)=$ $-0.6, \mathrm{P}>0.05)$. The mean SNQ total scores for those with and without co-morbid conditions were 94.93 (95\% confidence interval [CI], 80.34-109.53) and 100.73 (95\% CI, 86.51-114.94), respectively. Among the 26 VI children, 18 had mild low vision and 8 had moderate-to-severe low vision. There was no significant difference between the two levels of VI in SNQ total score $(t(24)=-1.425, P>0.05)$. The mean
SNQ total score for those with mild low vision was 93.00 (95\% CI, 79.55-106.45), and 107.25 (95\% CI, 98.03-116.47) for those with moderate-to-severe low vision. Therefore, all 26 cases could be treated as a group for further analysis.

\section{Reliability of Service Needs Questionnaire in visual impairment group}

The internal consistency of SNQ (Cronbach's alpha $=0.96$ ) measured in the VI group was similar to the magnitude reported in Leung et al's study, ${ }^{2}$ despite the difference in the samples used.

\section{Comparison of service needs among normal group, visual impairment group, and behavioural and learning problems group}

Owing to non-normality of the SNQ total score by group, the Kruskal-Wallis one-way ANOVA by ranks was conducted to examine if the mean rank SNQ total scores among the three groups were the same. The Dunn-Bonferroni tests were further applied to locate where the differences existed if the mean rank SNQ total scores were not the same.

The Kruskal-Wallis test was significant $\left(X^{2}(2)=80.928, P<0.001\right)$ inferring that the mean rank SNQ total scores were not the same among the three groups. The Dunn-Bonferroni tests showed that the mean rank SNQ total score of the normal group was significantly lower than that in VI group $(\mathrm{z}=-4.042, \mathrm{P}<0.001)$ and $\mathrm{LB}$ group $(\mathrm{z}=-8.531$, $\mathrm{P}<0.001)$, respectively. The mean rank SNQ total score of VI group was slightly lower than that of the LB group, but the difference was not significant $(z=-2.380, P=0.052$; Table 2). Each SNQ item was further analysed by conducting Kruskal-Wallis test to examine if there was a difference among the three groups. Bonferroni correction was applied to control the family-wise type I error predefined as 0.05. All SNQ items had significant differences among the three groups.

Eight of the top 10 needs were common to the three groups. In the VI group, three of the top five needs included education, services in supporting study, and school support. For most SNQ items, the

TABLE 2. Kruskal-Wallis test of mean rank Service Needs Questionnaire total score and the multiple comparisons*

\begin{tabular}{|c|c|c|c|c|c|c|c|}
\hline \multirow[t]{2}{*}{ Measure } & $\begin{array}{l}\text { VI group } \\
(n=26)\end{array}$ & $\begin{array}{c}\text { Normal group } \\
(n=200) \dagger\end{array}$ & $\begin{array}{l}\text { LB group } \\
(n=43)\end{array}$ & \multirow[t]{2}{*}{$\begin{array}{c}\text { Chi } \\
\text { squared }\end{array}$} & \multirow[t]{2}{*}{ df } & \multirow[t]{2}{*}{$P$ value } & \multirow[t]{2}{*}{ Multiple comparisons $\ddagger$} \\
\hline & Mean rank & Mean rank & Mean rank & & & & \\
\hline SNQ total score & 176.38 & 110.83 & 222.38 & 80.928 & 2 & $<0.001$ & $\begin{array}{l}\text { LB group }>\text { normal group }(P<0.001) \\
\text { VI group }>\text { normal group }(P<0.001) \\
\text { VI group = LB group }(P=0.052)\end{array}$ \\
\hline
\end{tabular}

Abbreviations: LB = learning and behavioural problems; SNQ = Service Needs Questionnaire; VI = visual impairment

* Cases with missing SNQ total score were excluded from analysis

$\dagger$ In the normal group, participants with developmental disabilities were also excluded from analysis

$\neq$ Experiment-wise type I error rate was set at 0.05. P was a single test type I error rate 
VI group scored significantly higher than the normal group but similar to the LB group. For a few items such as "I need to learn how to deal with stress", "I need emotional support", and "Children affect the relationship between spouse", the VI group scored significantly lower than the LB group but similar to the normal group. On the item "Spouse disagrees with me about fostering children", the VI group had lower score compared with the normal group. The mean scores of each SNQ item are listed in Table 3.

\section{Coping and functioning in academic and recreational activities}

Regarding coping in school and functioning in academic activities, most of the children with VI were receiving some form of school accommodation and support. The support included seating arrangement $(n=25,97 \%)$, enlargement of font size $(n=18,70 \%)$, assistance by peers in copying work and classroom activities $(n=7,27 \%)$, and use of visual aids and assistive devices $(\mathrm{n}=3,12 \%)$. Physical exercise and mathematics were reported as the most favourite subjects, while Chinese and English were the most difficult subjects for these children.

All children reported encountering difficulties during classroom activities; examples included difficulties with handwriting, reading, reading comprehension and memory, ball games, as well as cutting and pasting activities. Besides difficulties encountered during class, around one-fifth $(n=5)$ reported encountering difficulties during recess or lunch time due to lack of friends and peers to play with and difficulties in attending outdoor activities.

Many ( $\mathrm{n}=16,62 \%)$ had joined some form of extra-curricular activities, both indoor and outdoor. Swimming, dancing, ping-pong ball, and drawing were some examples of their favourite activities. Some of the difficulties described were problems with sustaining the practice, visual motor coordination, communication with classmates, and

TABLE 3. Mean scores of Service Needs Questionnaire items by group

\begin{tabular}{|c|c|c|c|}
\hline Item & VI group $(n=26)$ & Normal group $(n=200)$ & LB group $(n=43)$ \\
\hline I need more information about children's future education & 4.54 & 3.85 & 4.56 \\
\hline I need to know how to help my children & 4.50 & 3.36 & 4.53 \\
\hline Children need more services in study support & 4.42 & 3.29 & 4.63 \\
\hline Children need more systematic services & 4.35 & 3.21 & 4.60 \\
\hline School should provide more support to my children & 4.31 & 3.16 & 4.67 \\
\hline I need help in seeking services & 4.27 & 3.07 & 4.47 \\
\hline I need to know more about aiding children's study & 4.23 & 3.67 & 4.67 \\
\hline I need more information about children & 4.23 & 3.52 & 4.35 \\
\hline School should allocate more resources to support my children's study & 4.12 & 3.15 & 4.65 \\
\hline I worry about children's future & 4.08 & 3.15 & 4.21 \\
\hline I need to know more about dealing with children's emotion and behaviour & 4.00 & 3.53 & 4.58 \\
\hline Children need more training services hosted by professionals & 3.96 & 2.99 & 4.58 \\
\hline Children need more services in supporting emotion and behaviour & 3.81 & 2.91 & 4.35 \\
\hline Children make me feel stressful & 3.69 & 2.61 & 4.07 \\
\hline I need my spouse to share the burden in fostering children & 3.54 & 2.99 & 4.49 \\
\hline Few teachers have adequate knowledge about children having specific needs & 3.54 & 3.31 & 4.07 \\
\hline Children make me feel helpless & 3.38 & 2.31 & 3.86 \\
\hline Unprofessional school supporting services & 3.27 & 2.55 & 4.30 \\
\hline Children feel stressful about themselves & 3.23 & 2.81 & 4.16 \\
\hline Children make family members feel stressful & 3.23 & 2.38 & 3.77 \\
\hline Few teachers accept children having specific needs & 3.23 & 2.33 & 3.84 \\
\hline I need to learn how to deal with stress & 2.88 & 2.82 & 3.93 \\
\hline I need support in explaining children's situation to the family members & 2.69 & 2.70 & 3.65 \\
\hline Spouse lacks information about children & 2.65 & 2.54 & 3.49 \\
\hline I need emotional support & 2.58 & 2.26 & 3.60 \\
\hline Spouse disagrees with me about fostering children & 2.46 & 2.74 & 3.35 \\
\hline Children affect the relationship between spouse & 2.19 & 2.16 & 3.40 \\
\hline
\end{tabular}

Abbreviations: $L B=$ learning and behavioural problems; $\mathrm{VI}$ = visual impairment 
classmates playing tricks on them. Around one-third $(n=8)$ reported difficulties in leisure activities during school holidays, including the need for extra care in crowded areas, extra protection when exposed to sunlight, and some behavioural problems such as talking loudly and offending other children. A majority of them $(n=20,77 \%)$ did not join any selfhelp parent group as many did not feel the need, and most could not afford the time to join. Some descriptive answers on the difficulties encountered are listed in Table 4.

\section{Discussion}

Vision is our major sense and children with VI face many challenges and obstacles. In this study, needs expressed by parents having children with VI were significantly higher than those of parents of mainstream school children without SEN. The top five needs expressed by parents of VI children are on need for information and services. In particular, these parents expressed the need for more information and services on future education and school support despite receiving some degree of accommodation at school. This may be related to the general phenomenon among parents in Hong Kong who predominantly focus on academic achievement versus recreational and leisure activities. Meanwhile, these parents might not be fully aware of the kind of support available at school. The implication is for us to work closely with the education sector to make the school support service more transparent for the parents. By maintaining necessary case monitoring, we could give continuous feedback to the school based on a child's individual and changing needs.

Needs expressed by parents in the VI group were significantly higher than those in the normal group, but similar to those in the LB group. Children with VI, in addition to their unique obstacles in mainstream schools, also face some common difficulties of adapting and adjusting academically, socially, and behaviourally just like other children with SEN. Compared with parents of the normal group, parents of the VI group perceived more stress and, thus, more needs. Besides, nearly half the children in VI group had co-morbidities, including learning and behavioural problems. They might experience similar challenges at school leading to similar impact on their parents and families as those in the LB group. Despite the insignificant group difference between the VI and the LB groups, we noted that more parents from the LB group endorsed items related to stress, emotions, and effect on relationship with spouse from the item analysis. From this, it is believed that parents of the VI group might experience relatively less stress and turmoil resulting from children's learning and behavioural challenge as compared with the LB group. As children with VI are often diagnosed at an early age, it is speculated that their parents might have better adjustment and more mutual support in caring for them.

There were some limitations in this study, including the small sample size. As compared to the other developmental disabilities, the incidence of VI was relatively low, affecting $0.1 \%$ of the school-age population and $0.4 \%$ of children with all developmental disabilities. ${ }^{14}$ In Hong Kong, most children with significant developmental disabilities, including those with severe low vision or blindness, receive education in special schools. Children with milder developmental disabilities, including those with mild-to-moderate low vision, are integrated in mainstream schools with support from teachers and special schools. According to the statistics provided by the Education Bureau, the total number of school children with VI attending mainstream primary schools was 40 in year 2006/07, 40 in 2007/08, and 50 in 2008/09. The 30 cases in this study were recruited from different regions of Hong Kong during the study period and this cohort, therefore, represents the majority of children with VI attending mainstream schools in Hong Kong.

TABLE 4. Some direct quotes regarding the ability of children in coping and functioning in academic and recreational activities

\begin{tabular}{ll}
\hline Subjects/activities & Difficulties encountered \\
\hline Chinese & Too many strokes〔太多筆劃〕 \\
& Often makes error in handwriting〔易寫錯字〕 \\
& Difficulty in copying〔抄寫有困難〕 \\
& Difficulty in reading words〔睇字困難〕 \\
& Cannot read the small characters clearly〔細字看不清楚〕 \\
& Difficulty in cutting paper〔剪紙困難〕 \\
Visual art & Difficulty in cut-and-paste work〔難於剪貼〕 \\
& Difficulty in catching/throwing ball〔接/發球都有困難〕 \\
Physical education & Clumsy in catching ball〔接球不夠靈活〕 \\
& Get lost easily〔走散〕 \\
Extra-curricular and leisure & Need extra care when there are too many people around〔人太多時, 要多加照顧〕 \\
& Cannot be exposed to the sun, restricting the choice of venue〔不能雷太陽, 局限活動場地〕 \\
\end{tabular}


On the other hand, the VI group was not a homogeneous group and nearly half had other comorbid conditions, which are common among children with VI. The VI group with co-morbidities is expected to express greater needs. However, this was not observed in our study, probably due to the small sample size. The other limitation might be the possible self-selection bias in data collection. As voluntary participation was sought in the LB group, parents with high service needs might have been more eager to participate, leading to bias. The normal group was selected by convenience sampling, and the grade, age, and gender distributions of the sampled subjects in each school were not matched with those of all students in each school. This normal group might not represent all the mainstream primary schools.

Currently, the Education Bureau provides educational support for these children through school teachers, with resource help from special schools for VI children. Support includes assistive facilities and visual aids, accommodation in school activities and examination. It is encouraging to note that these children are enjoying a variety of extra-curricular activities despite the difficulties. Nonetheless, more facilitation of peer support and school integration is needed for these students both during classroom and extra-curricular activities. As most of these children should have needed visual aids and assistive devices to optimise their residual vision, the user rate noted was far below our expectation. More systematic work on education and training for parents will be needed to empower them with the knowledge and skills for helping their children, and to raise their awareness of local community resources. On the whole, parents are less aware of the availability of self-help support groups. Fostering and encouragement of parent support groups would be beneficial to the advocacy and support of rehabilitation planning for children with VI.

In this study, the needs of parents of children with VI in mainstream school were measured using a standardised and validated tool. With a relatively low incidence of children with disability, and the nature of common co-morbid conditions, it would be beneficial to have pooled data from different regions, including the education and hospital sectors, to shed more light on the future planning of support services for these children and their families. More study on the various modes of accommodation for children with VI and more collaborative work among different partners working in the field of rehabilitation will foster better service for these children and their families.

\section{Acknowledgements}

Our special thanks to Dr Cynthia Leung for her critical reading and Mr Morris Wu for the statistical analysis and technical editing. We would like to express our gratitude to all the parents who have participated in this study.

\section{References}

1. Hendriks AH, De Moor JM, Oud JH, Franken WM. Service needs of parents with motor or multiply disabled children in Dutch therapeutic toddler classes. Clin Rehabil 2000;14:506-17.

2. Leung C, Lau J, Chan G, Lau B, Chui M. Development and validation of a questionnaire to measure the service needs of families with children with developmental disabilities. Res Dev Disabil 2010;31:664-71.

3. Rosenbaum PL, King SM, Cadman DT. Measuring processes of caregiving to physically disabled children and their families. I: Identifying relevant components of care. Dev Med Child Neurol 1992;34:103-14.

4. Sloper P, Turner S. Service needs of families of children with severe physical disability. Child Care Health Dev 1992;18:259-82.

5. Nitta O, Taneda A, Nakajima K, Surya J. The relationship between the disabilities of school-aged children with cerebral palsy and their family needs. J Phys Ther Sci 2005;17:103-7.

6. Dote-Kwan J, Chen D, Hughes M. Home environments and perceived needs of Anglo and Latino families of young children with visual impairments. J Vis Impair Blind 2009;103:531-42.

7. Leyser Y, Heinze T. Perspectives of parents of children who are visually impaired: implications for the field. RE:view 2001;33:37-48.

8. Rahi JS, Manaras I, Tuomainen H, Hundt G. Health services experiences of parents of recently diagnosed visually impaired children. Br J Ophthalmol 2005;89:2138.

9. Wong SY, Wong TK, Martinson I, Lai AC, Chen WJ, He YS. Needs of Chinese parents of children with developmental disability. J Learn Disabil 2004;8:141-58.

10. Population by age group and sex, End-2012. Available from: http://www.censtatd.gov.hk/hkstat/sub/sp150.jsp?ta bleID=002\&ID=0\&productType=8. Accessed 31 Oct 2013.

11. Lo PW. Children with visual impairment: experience at Child Assessment Service (CAS). Child Assessment Service Epidemiology and Research Bulletin. In press.

12. Hong Kong Government. White Paper on Rehabilitation: Equal opportunities and full participation: A better tomorrow for all. Hong Kong: HKSAR Government; 1995.

13. IBM Corp. Released 2010. IBM SPSS Statistics for Windows, Version 19.0. Armonk, NY: IBM Corp.

14. Snyder TD, Tan AG, Hoffman CM. Children 3 through 21 years old served in federally supported programs for the disabled, by type of disability: Selected years, 1976-77 through 2003-04. In: Snyder TD, Tan AG, Hoffman CM. Digest of education statistics 2005 (NCES 2006-030). New York: Institute of Educational Sciences; 2006: 81. 